\title{
The Successful Treatment of Deep Soft-tissue Calcifications with Topical Sodium Thiosulphate and Acetazolamide in a Boy with Hyperphosphatemic Familial Tumoral Calcinosis due to a Novel Mutation in FGF23
}

\author{
(1) Hakan Döneray1,2, (1) Ayşe Özden¹, (1) Kadri Gürbüz3 \\ ${ }^{1}$ Atatürk University Faculty of Medicine, Department of Pediatric Endocrinology, Erzurum, Turkey \\ ${ }^{2}$ Atatürk University, Clinical Research Development and Design Application and Research Center, Erzurum, Turkey \\ ${ }^{3}$ Atatürk University Faculty of Medicine, Department of Pediatrics, Erzurum, Turkey
}

\section{What is already known on this topic?}

The central point of treatment in hyperphosphatemic familial tumoral calcinosis (HFTC) is to control the serum phosphorus level. In addition to low phosphate diet, medical therapies including phosphate binders, calcitonin, bisphosphonates, calcium channel blockers, corticosteroids, acetazolamide, probenecid and colchicine, have been used in different combinations. However, their success is variable and the main concern is the limited resolution of tumoral calcifications. Finally, topical sodium thiosulfate (STS) has been found to be effective only in superficial soft-tissue calcifications.

What this study adds?

We found a novel homozygous mutation in FGF23 in a patient with HFTC and also used a new combined therapy with topical STS and acetazolamide. Deep soft-tissue calcifications resolved completely with this treatment, with no relapse for three years. The findings in our case suggest that the combination of topical STS and acetazolamide added to phosphate-lowering agents may be effective in resolving deep soft-tissue calcifications in HFTC.

\section{Abstract}

Hyperphosphatemic familial tumoral calcinosis (HFTC) is a rare autosomal recessive disorder. Topical sodium thiosulfate (STS) and acetazolamide can be a safe and effective treatment for patients who do not respond to conventional therapy for ectopic calcifications. We report the successful treatment of deep soft-tissue calcifications with topical STS and acetazolamide in a boy diagnosed with HFTC due to a novel homozygous mutation of FGF23.

Keywords: Hyperphosphatemic familial tumoral calcinosis, sodium thiosulphate, acetazolamide, tumoral calcinosis, children

\section{Introduction}

Hyperphosphatemic familial tumoral calcinosis (HFTC) (OMIM 211900) is a rare autosomal recessive disease characterized by decreased renal phosphate excretion, hyperphosphatemia, and tumor-like subcutaneous softtissue calcifications around large joints. This disorder is caused by inactivating autosomal recessive mutations in three genes, including fibroblast growth factor 23 (FGF23), polypeptide $\mathrm{N}$-acetylgalactosaminotransferase 3 (GALNT3), and klotho (KL). Serum FGF23, encoded by FGF23, is responsible for the inhibition of both sodium phosphate cotransporter in proximal renal tubules and $1 \alpha$ - hydroxylase enzyme expression. So, FGF23 increases urinary phosphate excretion while decreasing serum 1.25-dihydroxy vitamin D $\left[1.25(\mathrm{OH})_{2} \mathrm{D}\right]$ level.
Address for Correspondence: Hakan Döneray MD, Atatürk University Faculty of Medicine, Department of

Pediatric Endocrinology; Atatürk University, Clinical Research Development and Design Application and Research Center, Erzurum, Turkey

Phone: +90 5359444307 E-mail: hdoneray@hotmail.com ORCID: orcid.org/0000-0002-9774-3649
Conflict of interest: None declared Received: 12.11 .2020 Accepted: 03.02.2021

${ }^{\circ}$ Copyright 2022 by Turkish Society for Pediatric Endocrinology and Diabetes

The Journal of Clinical Research in Pediatric Endocrinology published by Galenos Publishing House. 
Klotho, a co-receptor protein encoded by $K L$, together with FGF23 receptor should be intact to elicit these effects of FGF23. GALNT codes the enzyme named UDP-N-acetyl-alpha-D galactosamine or polypeptide $\mathrm{N}$-acetylgalactosaminyltransferase-3. This enzyme protects intact FGF23 from enzymatic degradation. Therefore, any mutations in GALNT3 lead to a decrease in serum FGF23 level. The net effects of these three intact genes are to decrease serum phosphorus and $1.25(\mathrm{OH})_{2} \mathrm{D}$ levels. However, any inactivating mutation in these genes causes hyperphosphatemia and elevated serum $1.25(\mathrm{OH})_{2} \mathrm{D}$ level due to decreased renal tubular phosphate excretion and increased $1 \alpha$-hydroxylase activity, respectively $(1,2,3,4)$. Serum calcium, alkaline phosphatase, and parathyroid hormone levels in the patients with HFTC are typically normal. Therefore, HFTC is considered to be the biochemical mirror of disorders that lead to excessive serum FGF23 levels, such as tumor-induced osteomalacia, $\mathrm{X}$-linked hypophosphatemic rickets, and autosomal dominant hypophosphatemic rickets (5).

The treatment of HFTC is not standardised. The main components of treatment are low phosphate diet and drugs that bind phosphate or promote phosphate excretion from the kidneys. However, clinical response to these treatments is quite variable, and the medical treatment of ectopic calcifications can be difficult with conventional treatment $(5,6)$. Surgical intervention can be performed in subjects with functional impairment or severe pain, but it is not routinely undertaken because calcinosis often recurs (7).

Here, we report the successful treatment of deep softtissue calcifications with topical sodium thiosulfate (STS) and acetazolamide in a boy diagnosed with HFTC due to a novel homozygous mutation of FGF23. The findings in this case suggest that the combination of topical STS and acetazolamide added to phosphate-lowering agents may be effective in resolving deep soft-tissue calcifications in HFTC.

\section{Case Report}

A 15-year-old boy who was followed up by the orthopedic clinic presented with a new, painful and progressive swelling in his right hip for a year. Surgical resections were performed four times in the last five years due to similar swelling in his left hip and both elbows. Histopathologic examination of the tissues was reported as tumoral calcinosis. He was not receiving any medical treatment. There was no history of fever, polyuria, kidney stones or fractures. His parents were third degree relatives. The rest of his family background was unremarkable. At admission, body weight and height were $46.0 \mathrm{~kg}$ [-1.8 standard deviation (SD)] and $157.5 \mathrm{~cm} \mathrm{(-1.8}$ SD), respectively. Physical examination revealed a $4 \times 5 \mathrm{~cm}$ firm swelling in the right hip, which caused pain and limited hip range of motion with passive movements. Except for the surgical scars on the relevant joints, other examination findings were unremarkable. Laboratory tests, including complete blood count, urogram, blood gases, serum glucose, blood urea nitrogen, creatinine, sodium, potassium, magnesium, calcium, alkaline phosphatase, parathormone, 25-hydroxy vitamin D, liver and thyroid function tests, and spot urine calcium/creatinine ratio were within normal limits. Serum phosphorus level was $7.8 \mathrm{mg} / \mathrm{dL}(\mathrm{N}=2.5-5.0$ $\mathrm{mg} / \mathrm{dL}$ ) (Table 1). X-ray and magnetic resonance imaging examination confirmed the extra-osseous calcification (Figures 1A, 2A, and 3A). Genetic analysis of GALNT3 gene was normal. However, FGF23 exon 1 analysis revealed a novel homozygous guanine-to-cytosine transversion at position 162 (c.162G > C), resulting in a novel glutamine (Q)-to-histidine $(\mathrm{H})$ amino acid substitution at position 54 (p.Q54H) (Figure 4). The parents were heterozygous for the same variant and their clinic and laboratory findings were normal. A low-phosphate diet and an oral phosphate binding agent, sevelamer (40 mg/kg/d, three doses), were given. At the end of one year of this treatment, although the patient had good compliance with the conventional therapy, the size of the swelling did not regress or worsen, new lesions did not develop, and serum phosphorus level was $6.1 \mathrm{mg} / \mathrm{dL}$ (Table 1). At that time, oral acetazolamide $(20 \mathrm{mg} / \mathrm{kg} / \mathrm{d})$ and

\begin{tabular}{|c|c|c|c|c|c|c|}
\hline Follow up & $\mathrm{Ca}(\mathrm{mg} / \mathrm{dL})$ & $P(m g / d L)$ & ALP (IU/L) & PTH (pg/mL) & 25(OH)D (ng/mL) & Spot urine $\mathrm{Ca} / \mathrm{Cr}$ \\
\hline $\begin{array}{l}\text { On admission (low phosphate diet and sevelamer } \\
\text { was started) }\end{array}$ & 10 & 7.8 & 186 & 18.9 & 20.2 & 0.06 \\
\hline $\begin{array}{l}12 \text { months later (acetazolamide and STS cream } \\
\text { were added to the therapy) }\end{array}$ & 9.8 & 6.1 & 165 & 28.2 & 19.5 & 0.06 \\
\hline $\begin{array}{l}15 \text { months later (continued with low phosphate } \\
\text { diet + sevelamer, and acetazolamide + STS cream } \\
\text { were stopped) }\end{array}$ & 9.3 & 4.2 & 93 & 32 & 20.5 & 0.04 \\
\hline 51 months later (low phosphate diet + sevelamer) & 9.2 & 3.9 & 102 & 35 & 21 & 0.02 \\
\hline
\end{tabular}

Ca: calcium, P: phosphorus, ALP: alkaline phosphatase, PTH: parathyroid hormone, 25(OH)D: 25-hydroxy vitamin D, Cr: creatinine, STS: sodium thiosulfate 
a topical cream consisting of STS $\left(\mathrm{Na}_{2} \mathrm{~S}_{2} \mathrm{O}_{3}\right)$ dispersed into a Galen's cerate (cold cream, from 4/96 to 10/90 wt/wt) were added to the therapy. A thin layer of cream was applied over the swelling twice a day. The mass disappeared dramatically both clinically and radiologically after 3 months (Figures 1B, $2 \mathrm{~B}$, and $3 \mathrm{~B}$ ). The patient tolerated this treatment well and no side effects were detected. At that time, acetazolamide and topical STS treatments were discontinued while low phosphate diet and sevelamer treatments were continued. Three years later, there was still no calcification or newly developed lesion on the radiograph of the right hip (Figure 1C). The laboratory tests performed at first admission were repeated at each visit and serum phosphorus levels were within normal limits (Table 1).

\section{Discussion}

In most cases with deep soft-tissue calcifications due to HFTC, the therapeutic effects of drugs are either negligible or short-lived. Given these disappointing results, the combination of topical STS and acetazolamide added to phosphate-lowering agents, as in our case, appears to provide a promising contribution in resolving deep softtissue calcifications. Additionally, this case report broadens the spectrum of FGF23 mutations.

FGF23, encoded by FGF23, is the primary regulator of extracellular phosphate concentration. FGF23 synthesized in bone is released into the circulation and causes urinary phosphate excretion by acting on the proximal renal tubule. In addition, FGF23 decreases renal production of $1.25(\mathrm{OH})_{2} \mathrm{D}$ by inhibiting $1 \alpha$-hydroxylase, thereby reducing intestinal phosphate absorption. Activating mutations in FGF23 are

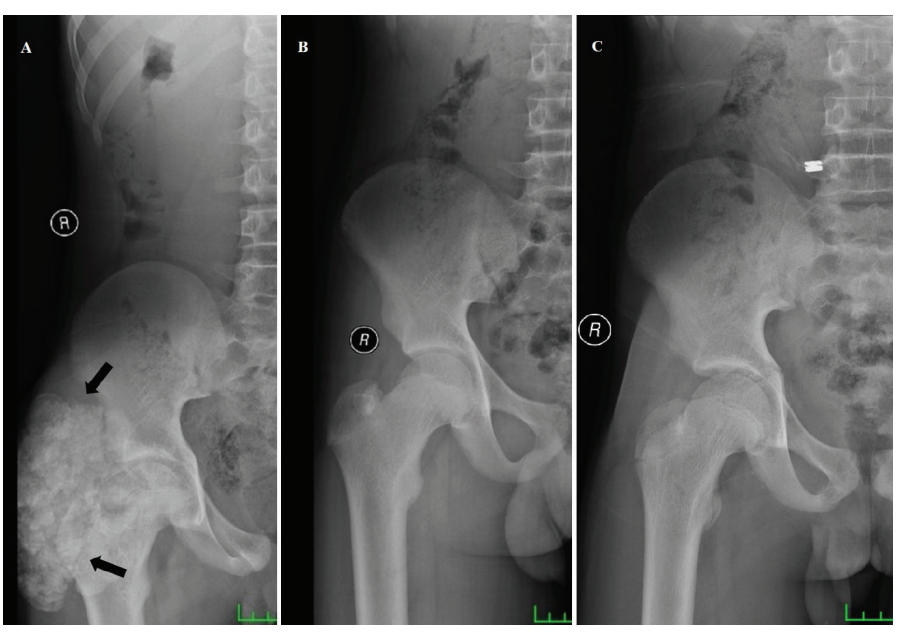

Figure 1. (A) Soft tissue calcification on the anteroposterior radiograph of the right hip before the treatment (black arrows). (B) 3 months after topical STS and acetazolamide. (C) 36 months after acetazolamide and topical STS treatments were stopped

STS: sodium thiosulfate

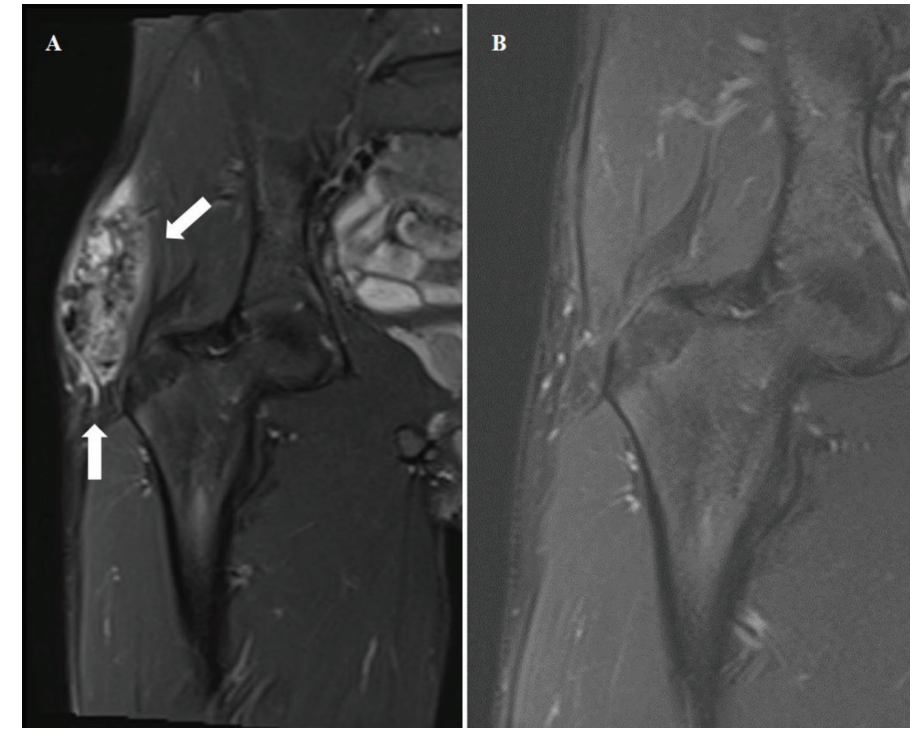

Figure 2. (A) Frontal plan magnetic resonance imaging showing soft tissue calcification around the right hip before the treatment (white arrows). (B) 3 months after topical STS and acetazolamide STS: sodium thiosulfate

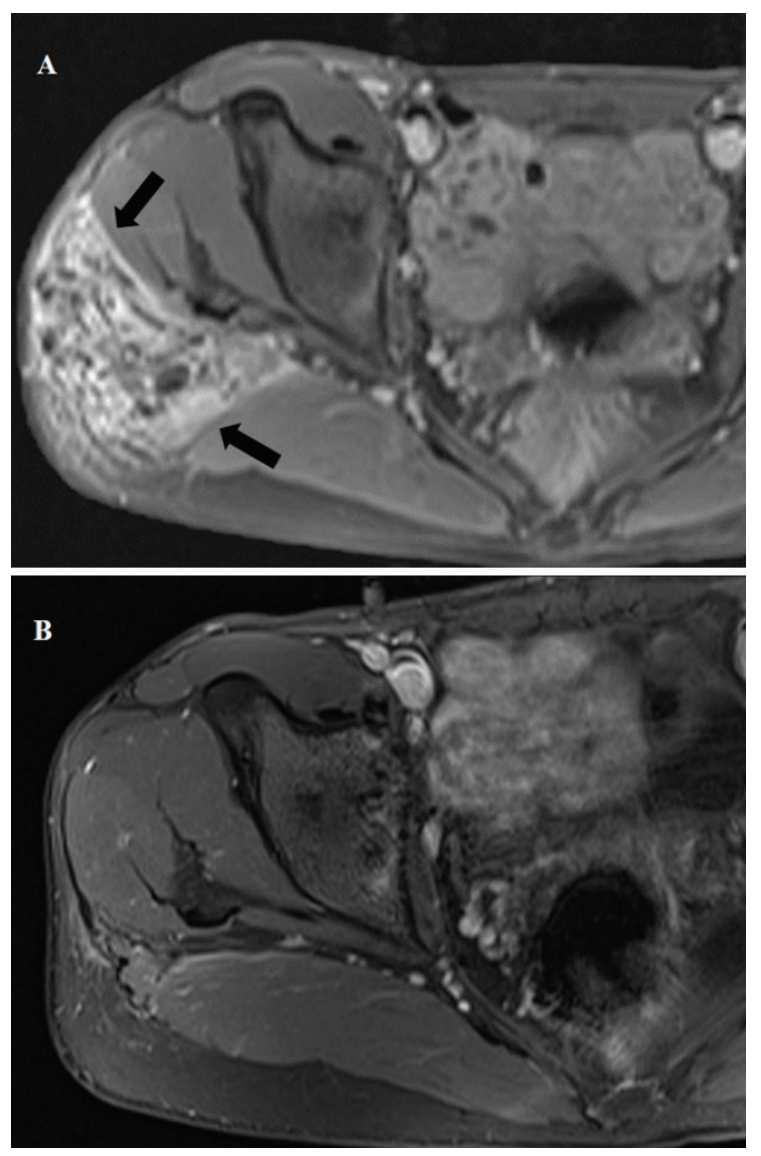

Figure 3. (A) Horizontal plan magnetic resonance imaging showing soft tissue calcification around the right hip before the treatment (black arrows). (B) 3 months after topical STS and acetazolamide

STS: sodium thiosulfate 
inherited in an autosomal dominant manner and lead to configurational changes that prevent inactivation of intact FGF23, resulting in autosomal dominant hypophosphatemic rickets. On the other hand, the mode of inheritance of inactivating mutations in FGF23 is autosomal recessive and they cause inadequate FGF23 production, resulting in HFTC $(1,8)$. A cytosine substitution for guanine at position 162 (c.162G > C) in FGF23 exon 1 has been reported as a likely pathogenic heterozygous variant, coded rs193922701 in ClinVar and Mutation Taster databases for autosomal dominant hypophosphatemic rickets. However, our patient was homozygous for the same variant and this resulted in glutamine (Q)-to-histidine (H) amino acid substitution at position 54 (p.Q54H) and clinical and laboratory findings consistent with HFTC. In addition to these results, Garringer et al (9) reported the transversion of cytosine to adenine at position 160 (c.160C > A) in FGF23 exon 1 of a patient with HFTC, resulting in glutamine (Q)-to-lysine (K) amino acid substitution at position 54 (p.Q54K). All these findings suggest that this codon encoding glutamine amino acid in FGF23 exon 1 is sensitive to base changes. In order to evaluate the pathogenicity of the novel variant, we used in silico prediction tools, mutation databases (Human Gene Mutation Database and Clinvar), allele frequency in population studies [1000 Genome, Genome Aggregation Database (gnomAD)], segregation analysis and American College of Medical Genetics and Genomics criteria (10). We identified that this variant had not been found in genomAD and that its site had been a highly preserved region across species. We performed segregation analysis to establish the risk of disease for this variant and found that p.Q54H could segregate with the disease phenotype by causing the neutral-polar acidic amino acid to be replaced with a basic one. To the best our knowledge, our patient is the first

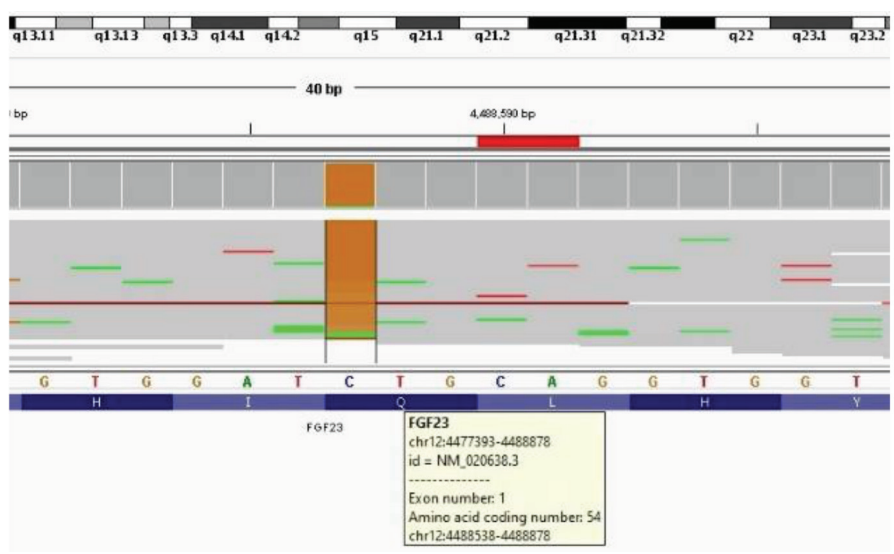

Figure 4. Sequence analysis of FGF23. A novel homozygous guanine-to-cytosine transversion at position 162 (c.162G > C), resulting in a novel glutamine (Q)-to-histidine $(\mathrm{H})$ amino acid substitution at position 54 (p.Q54H) case with HFTC resulting from a novel mutation (p.Q54H; c. $162 \mathrm{G}>$ C) of FGF23.

Data on the optimal treatment of HFTC are very limited. This is because HFTC is a very rare disease and there are no randomized clinical trials. All the treatments described are derived from case reports or small case series with varying success rates, possibly due to heterogeneous patient population and non-standardized methods. In addition, the criteria for success in treatment are highly variable. Some studies focus on the treatment effect on tumoral calcification size and symptomatic improvement while others focus on laboratory measurements such as changes in serum phosphate or urinary phosphate excretion (11). The central point of treatment in HFTC is to control the serum phosphorus level and reduce pain. Unless calcinosis causes the restriction of joint motion, surgery is not recommended because of frequent relapses. In addition to low phosphate diet, medical therapies including phosphate binders, calcitonin, bisphosphonates, calcium channel blockers, corticosteroids, acetazolamide, probenecid and colchicine have been used in different combinations. They have variable and limited success in completely resolving tumoral calcifications due to not adhering to the difficult dose regimen $(4,5,12)$. At the beginning of the treatment, we used a low phosphate diet and sevelamer as a phosphate binder. This approach prevented the progression of the swelling size and the formation of new tumors for a year. However, it failed to reduce the tumor size. Therefore, we added oral acetazolamide and topical STS to the treatment. Acetazolamide, a carbonic anhydrase inhibitor, causes phosphaturia by inducing proximal renal tubular acidosis (5). The exact mechanism of topical STS is unknown. However, it is suggested that STS induces calcium removal through chelation by creating metabolic acidosis and inhibits crystal formation and vascular calcification $(6,13)$. The first study in which topical STS was used for the local treatment of ectopic calcifications in HFTC patients was published in 2016 (6). In that study the ratio of STS dispersed into a Galen's cerate was from 10/90 to 25/75 wt/wt and no acetazolamide was used. The authors realized that topical STS alone might be effective for superficial soft tissue calcifications, but not deep ones. We used acetazolamide to take advantage of its synergistic effect in combination with lower doses of topical STS (4/96 to $10 / 90 \mathrm{wt} / \mathrm{wt}$ ) and found that this combined therapy was effective to completely eliminate deep soft-tissue tumoral calcifications in three months. This combination was also effective in keeping serum phosphorus levels within normal limits. These findings suggest that topical STS dosage should be determined individually, based on response to previous treatments, and topical STS may be more effective for deep soft-tissue calcifications when combined with 
acetazolamide. The optimal duration of topical STS therapy has not been established and there are no data on possible relapse after cessation of therapy. However, our case shows that a 3-month treatment is sufficient to remove the lesions. In addition, despite the discontinuation of acetazolamide and topical STS treatments, no new calcification occurred for three years under low phosphate diet and sevelamer treatment. It seems reasonable to continue low phosphate diet and sevelamer therapy and to preserve acetazolamide and topical STS treatments for possible new or recurrent calcifications. However, it should be kept in mind that our findings are observational and the clinical course of the patient cannot be fully explained with this treatment. Therefore, prospective, controlled, multicenter studies are required to verify treatment efficacy and optimize the treatment procedure in children with HFTC.

\section{Conclusion}

In conclusion, this report broadens the spectrum of FGF23 mutations. The soft-tissue calcifications in patients with HFTC may be difficult to treat with conventional drugs. At this point, topical STS and acetazolamide may be a safe and effective treatment. The dose of topical STS should be adjusted individually and its use with acetazolamide may be more effective in resolving deep soft-tissue calcifications.

\section{Acknowledgments}

We thank "Intergen Genetic Disorders and Diagnose Center" for genetic analysis in this patient.

\section{Ethics}

Informed Consent: Informed consent was obtained from the parents of the patient for publication of this case.

Peer-review: Externally peer-reviewed.

\section{Authorship Contributions}

Medical Practices: Hakan Döneray, Ayșe Özden, Kadri Gürbüz, Design: Hakan Döneray, Data Collection or Processing: Hakan Döneray, Ayşe Özden, Kadri Gürbüz, Analysis or Interpretation: Hakan Döneray, Ayşe Özden, Literature Search: Hakan Döneray, Ayşe Özden, Writing: Hakan Döneray.

Financial Disclosure: The authors declare that this study has received no financial support.

\section{References}

1. Benet-Pagès A, Orlik P, Strom TM, Lorenz-Depiereux B. An FGF23 missense mutation causes familial tumoral calcinosis with hyperphosphatemia. Hum Mol Genet 2005;14;385-390. Epub 2004 Dec 8

2. Topaz O, Shurman DL, Bergman R, Indelman M, Ratajczak P, Mizrachi M, Khamaysi Z, Behar D, Petronius D, Friedman V, Zelikovic I, Raimer S, Metzker A, Richard G, Sprecher E. Mutations in GALNT3, encoding a protein involved in O-linked glycosylation, cause familial tumoral calcinosis. Nat Genet 2004;36;579-581. Epub 2004 May 9

3. Ichikawa S, Imel EA, Kreiter ML, Yu X, Mackenzie DS, Sorenson AH, Goetz R, Mohammadi M, White KE, Econs MJ. A homozygous missense mutation in human KLOTHO causes severe tumoral calcinosis. J Musculoskelet Neuronal Interact 2007;7:318-319.

4. Finer G, Price HE, Shore RM, White KE, Langman CB. Hyperphosphatemic familial tumoral calcinosis: response to acetazolamide and postulated mechanisms. Am J Med Genet A 2014;164;1545-1549. Epub 2014 Mar 25

5. Ramnitz MS, Gourh P, Goldbach-Mansky R, Wodajo F, Ichikawa S, Econs MJ, White KE, Molinolo A, Chen MY, Heller T, Del Rivero J, Seo-Mayer P, Arabshahi B, Jackson MB, Hatab S, McCarthy E, Guthrie LC, Brillante BA, Gafni RI, Collins MT. Phenotypic and Genotypic Characterization and Treatment of a Cohort With Familial Tumoral Calcinosis/Hyperostosis-Hyperphosphatemia Syndrome. J Bone Miner Res 2016;31;1845-1854. Epub 2016 Sep 20

6. Jost J, Bahans C, Courbebaisse M, Tran TA, Linglart A, Benistan K, Lienhardt A, Mutar H, Pfender E, Ratsimbazafy V, Guigonis V. Topical Sodium Thiosulfate: A Treatment for Calcifications in Hyperphosphatemic Familial Tumoral Calcinosis? J Clin Endocrinol Metab 2016;101;2810-2815. Epub 2016 May 10

7. Tiwari V, Zahra F. Hyperphosphatemic Tumoral Calcinosis. In: StatPearls [Internet]. Treasure Island (FL): StatPearls Publishing; 2022 Jan. 2022 Feb 28. Available from: https://www.ncbi.nlm.nih.gov/books/ NBK572152/

8. Christov M, Jüppner H. Phosphate homeostasis disorders. Best Pract Res Clin Endocrinol Metab 2018;32;685-706. Epub 2018 Jun 18

9. Garringer HJ, Malekpour M, Esteghamat F, Mortazavi SM, Davis SI, Farrow EG, Yu X, Arking DE, Dietz HC, White KE. Molecular genetic and biochemical analyses of FGF23 mutations in familial tumoral calcinosis. Am J Physiol Endocrinol Metab 2008;295;929-937. Epub 2008 Aug 5

10. Richards S, Aziz N, Bale S, Bick D, Das S, Gastier-Foster J, Grody WW, Hegde M, Lyon E, Spector E, Voelkerding K, Rehm HL; ACMG Laboratory Quality Assurance Committee. Standards and guidelines for the interpretation of sequence variants: a joint consensus recommendation of the American College of Medical Genetics and Genomics and the Association for Molecular Pathology. Genet Med 2015;17;405-424. Epub 2015 Mar 5

11. Folsom LJ, Imel EA. Hyperphosphatemic familial tumoral calcinosis: genetic models of deficient FGF23 action. Curr Osteoporos Rep 2015;13;78-87.

12. Claramunt-Taberner D, Bertholet-Thomas A, Carlier MC, Dijoud F, Chotel F, Silve C, Bacchetta J. Hyperphosphatemic tumoral calcinosis caused by FGF23 compound heterozygous mutations: what are the therapeutic options for a better control of phosphatemia? Pediatr Nephrol 2018;33;1263-1267. Epub 2018 Mar 28

13. Burja S, Jovic A, Ekart R, Piko N, Miljkovic J, Breznik V. Successful treatment of extensive uremic calciphylaxis with intravenous sodium thiosulfate and its potential in treating various diseases of pathologic calcification. Acta Dermatovenerol Alp Pannonica Adriat 2019;28;3740 